\title{
The Denial of Opposite-Sex Couples’ Access to Civil Partnership as Discrimination?
}

\author{
Lucinda Ferguson* \\ Oriel College, Oxford
}

Keywords: ss1, 3(1)(a) Civil Partnership Act 2004 - civil partnership - Articles 8, 14 European Convention on Human Rights - Marriage (Same Sex Couples) Act 2013 discrimination - Wilkinson v Kitzinger and another (No 2) [2006] EWHC 2022 (Fam)

\section{The Decision of the High Court}

As a result of the extension of marriage via the Marriage (Same Sex Couples) Act 2013, same-sex couples can choose whether to secure formal legal recognition of their relationship via marriage or civil partnership. In Steinfeld and Keidan v Secretary of State for Education [2016] EWHC 128 (Admin), the claimant couple argued that sections 1 and 3(1)(a) of the Civil Partnership Act 2004, which restrict eligibility to enter into civil partnership to samesex couples, were incompatible with Article 14 of the European Convention on Human Rights taken together with Article 8, and sought a declaration of incompatibility under section 4 of the Human Rights Act 1998.

Andrews J dismissed their application for judicial review, reasoning on alternative grounds. Firstly, the claim did not fall within Article 14 read together with Article 8. Secondly, were the couples' claim seen to fall within the ambit of Article 14 read together with Article 8, differential treatment of same-sex and opposite-sex couples in terms of their access to civil partnership was objectively justified (para. 86). The High Court judgment in Steinfeld is important in four respects: first, it highlights the importance of seeing the couple's discrimination claim as equality-based, which means it is properly addressed by the courts, rather than Parliament; second, it demonstrates the impact of the uncertainty over the

\footnotetext{
* Iucinda.ferguson@law.ox.ac.uk. A more detailed version of this article was presented at the Family Law Bar Association's 2016 conference (Cumberland Lodge, 7 May 2016); and will be published in the Child and Family law Quarterly (forthcoming).
} 
relationship between domestic and ECtHR jurisprudence; third, it underlines the difficulties of relying on the Court of Appeal's earlier decision in Wilkinson v Kitzinger and another (No 2) [2006] EWHC 2022 (Fam) in this context; fourth, it evidences significant assumptions made in this context about both the immutability and flexibility in the meaning of civil partnership and marriage, as well as the nature and relevance of the public interest to any reform of civil partnership.

\section{The Correct Characterisation of the Claimant Couple's Discrimination Claim}

Whilst it is only a matter of emphasis (Moreau, 2013, p. 72), accurately characterising the nature of the couple's discrimination claim is key to assessing whether Andrews $\mathrm{J}$ was right to dismiss it. I suggest that Andrews J proceeded on the basis that the claim was libertybased whereas it is properly understood as equality-based. The former 'require[s] courts to make controversial moral judgments' (Moreau, 2013, p. 72) about the legal institution in question, whereas the latter requires the court to determine whether the law has 'fail[ed] to treat people as equals’ (Hellman, 2013, p. 51), which usually requires a comparative assessment.

The core of the couple's 'novel' claim (para. 7) relates not to the delay in reforming civil partnership, but to the substantive situation it has created in which there are more options for formal legal recognition of same-sex couples’ relationships than for opposite-sex couples’ relationships. She dismissed this claim on the basis that the ECHR requires only that the state provide 'a means' of formal recognition, such that

the denial of a further means of formal recognition which is open to same-sex couples, does not amount to unlawful state interference with the Claimants' right to family life or private life, any more than the denial of marriage to same-sex couples did prior to the enactment of the 2013 Act (para. 39).

But is the underlying basis of denial of access to civil partnership for opposite-sex couples post-extended marriage comparable to that of denial of access to marriage for same-sex couples who have access to civil partnership? I suggest not. The extension of marriage to same-sex couples via the Marriage (Same Sex Couples) Act 2013 ostensibly equalised treatment of same- and opposite-sex couples, which was not the case when same-sex couples had access only to civil partnership via the Civil Partnership Act 2004. Even if one dismisses the significance of the content differences between civil partnership and marriage, it was only 
with the extension of marriage that same- and opposite-sex couples shared the same formal legal status. This does not mean, however, that the Steinfeld couple's claim is one for the same treatment, denial of which is not necessarily discriminatory. Rather, it is one for equal concern and respect (cf. Hellman, 2013, p. 54), available only via access to a legal label, a legal institution that reflects the couple's ideological rejection of marriage. The couple's claim is thus equality-based, and there is no need or even space for the moral judgment required by a liberty-based discrimination claim.

\section{The Relationship between Domestic and ECtHR Jurisprudence}

Andrews J correctly notes that the ECtHR has never suggested that the ECHR imposes any requirements in respect of a particular form of recognition of an intimate relationship (paras. 52, 54). She also simply asserts the contentious point that domestic courts 'have no business overtaking' Strasbourg jurisprudence (para. 53). This represents a 'full mirror principle' approach to the correct interpretation of the requirement under section 2 of the Human Rights Act 1998 to 'take into account' the jurisprudence of the ECtHR and effectively treats the ECtHR as a fourth level of appeal.

But this is only one of three perspectives on the relationship between domestic and ECtHR jurisprudence, the other two being the 'anti-mirror principle' and the 'partial or semi-mirror principle' (Fenwick, 2012; cf. Lewis, 2007, p. 720). It is far from settled that the 'full mirror principle' is the correct approach (cf. Joint Committee on Human Rights, 2011, Q64, Lord Judge). Further, it is clear that the ECtHR is not intended to be a fourth level of appeal (Arden, 2010, p. 7) which places domestic courts in a relationship of deference rather than effective dialogue (p. 14). Andrews J's decision is thus vulnerable to challenge on this basis.

\section{The Court of Appeal's Decision in Wilkinson and the Importance of Labels}

Andrews J's reasoning emphasised the legal consequences of the institutions that regulate adult intimate relationships, and underplayed other aspects of marriage and civil partnership. She considered herself bound by judicial comity by Sir Mark Potter P’s reasoning in Wilkinson v Kitzinger and another (No 2) [2006] EWHC 2022 (Fam) unless the decision was ““clearly wrong”” (paras. 41, 85). In that case, Sir Mark Potter P held that it was sufficient to 
treat a foreign same-sex marriage as a civil partnership domestically, and it did not require to be treated as a marriage.

There are two difficulties with Andrews J's use of Wilkinson: first, her characterisation of the relationship between the issues raised in Wilkinson and Steinfeld; second, whether Sir Mark Potter P's rejection of the expressive aspect was sound even at the time of the original decision. In respect of the first issue, Andrews J suggested that the Wilkinson reasoning and outcome 'would apply with equal force' here (para. 9) and that Potter P 'had reached a similar conclusion (on stronger arguments)' (para. 40). But the cases raise distinct issues. At the time of the decision in Wilkinson, there was no European social consensus on the issue of marriage for same-sex couples at the time. This meant that the same-sex couple's discrimination claim in Wilkinson was liberty-based and required a moral judgment to be made about the nature of marriage. Here, the claim is equality-based, hence the reasoning in Wilkinson does not apply with equal force.

In respect of soundness at the time, Potter P suggested that, to bring a claim within Article 8, 'it is necessary to focus on an aspect of a person’s private or family life' (para. 80) or, in other words, the impact needed to be directly functional. By contrast, the petitioner in Wilkinson emphasised the 'symbolic status' of marriage (para. 5; discussed in Steinfeld, para. 32). Following Wilkinson, Andrews J focused on the functional impact of legal consequences alone (paras. 37-39), hence could conclude that 'the impact is light' and there was a 'lack of appreciable impact' (para. 72) attributable to the denial of access to civil partnership for opposite-sex couples.

But marriage is a social institution and the direct substantive, functional consequences of formal legal recognition are only a part thereof. Andrews $\mathrm{J}$ is thus arguably mistaken to conclude that the denial of the status 'has placed no constraints on their social intercourse' (para. 37). Collective intentionality is critically important to the social meaning of intimate relationships, for both individuals within those relationships and in society more generally.

More fundamentally, I suggest that the UK Government has itself removed the justifiability of excluding the value of labels from the analysis. In extending marriage to same-sex couples but leaving in place the contentious substantive differences, no matter how limited, the Government must be treated as having acknowledged the centrality of labels and 
terminology. Under the Marriage of Same Sex Couples (Conversion of Civil Partnership) Regulations 2014, introduced under powers conferred by sections 9 and 18 of the 2013 Act, it is possible to 'convert' civil partnerships into marriages. Haskey (2016) found that, in the second half of 2015, the total number of 'conversions' was double the number of 'nonconversion' marriages between same-sex couples (p. 46). The popularity of 'conversions' is arguably explained at least in part by individuals attaching weight to labels. As a result, it is not clear that the Wilkinson dismissal of the claim under Article 8 read together with Art 14 ECHR was sound even at the time of the original decision.

\section{Assumptions about Marriage, Civil Partnership, and the Public Interest}

The foregoing discussion of the expressive aspects of the institution of civil partnership demonstrates the importance of determining the true meaning of civil partnership and marriage. The Steinfeld couple's claim assumes that civil partnership as an institution is capable of change and, indeed, has been transformed by the extension of marriage to samesex couples. If correct, the justifiability of civil partnership post-'extended marriage’ is entirely separate from the justifiability of civil partnership pre-'extended marriage’. Andrews $\mathrm{J}$ assumed that the meaning of civil partnership was immutable. She emphasised the original purpose of civil partnership (eg. para. 74) and argued that, just as the Civil Partnership Act 2004 was not within the ambit of Article 8 ECHR prior to the enactment of the Marriage (Same Sex Couples) Act 2013, so it was not afterwards (para. 55). By contrast, the Steinfeld couple's rejection of marriage on ideological grounds (para. 2) is underpinned by an assumption that marriage is immutable. Whilst not argued for by the Government or posited by Andrews J, I suggest that the justifiability of constraining the couple's choice of status relationships to marriage arguably requires seeing the meaning of marriage as capable of change.

I contend that the meanings of both institutions should be seen as capable of change. The history of marriage itself makes that plain. In his oft-cited decision in Hyde v Hyde (1866) LR 1 P\&D 130, Lord Penzance defined marriage as ...the voluntary union for life of one man and one woman to the exclusion of all others...' (p. 133). Yet, that meaning was transformed by the Marriage (Same Sex Couples) Act 2013. This also indirectly and immediately altered the meaning of civil partnership. The equalisation of access to marriage for opposite-sex and same-sex couples on liberty-based grounds meant that no liberty-based arguments were 
required to underpin access to civil partnership by opposite-sex couples; civil partnership had become an alternative means of formal legal recognition for both relationship-types on equality-based grounds. As a result, Andrews J was mistaken in her conclusion that oppositesex couples were not disadvantaged in practice in the intervening short-term period (paras. 71-72, 86) prior to the Government's decision on the future of civil partnership.

As characterised by Andrews J, the couple 'do not suggest that there is any substantive difference between civil marriage and civil partnerships in terms of the legal rights and responsibilities they accord...' (para. 4). But the content differences in the treatment of same-sex couples across civil partnership and marriage have been immutable (summarised by Department for Culture, Media, and Sport, 2014, Appendix A). The Steinfeld couple's argument overlooks these differences, and is premised on same-sex couples having the full choice of the form of formal legal recognition of their relationship open to them, whereas in fact same-sex couples are denied that choice. But in focusing on the demand for equal access to civil partnership, do we not risk obfuscating the ongoing pernicious status hierarchy between opposite-sex and same-sex couples? If a couple could previously justifiably reject marriage for ideological concerns about its patriarchal nature, should they not similarly reject civil partnership and marriage as extended to same-sex couples for their nowheteropatriarchal nature?

As a status relationship, the public interest shapes and is affected by the nature of civil partnership. Yet both the claimant couple and Andrews J make unjustifiable assumptions about the nature of that public interest. The Steinfeld couple's argument that they should be 'entitled' to choose the form of legal recognition by which they acquire legal rights and responsibilities (para. 4) assumes the state interest either is irrelevant or, to the extent it is relevant, supports or is neutral toward their claim. The couple's claim focuses on legal recognition but overlooks the implication of the automatic flow of legal consequences from recognition for status relationships, which is of the essence to status relationships. But only a state interest can justify this application of legal consequences. Whilst Andrews J acknowledges the public interest in marriage (para. 1), she does not examine its relevance to determining whether access to civil partnership should be extended to opposite-sex couples.

To the extent that the Steinfeld couple's discrimination claim is equality-based, which is not how Andrews J understood the claim, this avoids the need to consider the public interest. But 
the longer-term future of civil partnership, which is to be settled by Parliament, requires direct consideration and resolution of the public interest. This is particularly important because the Steinfield couple's claim demonstrates the real risk of inverting the hierarchy of marriage and civil partnership as status relationships, with the ostensibly more modern civil partnership being seen as more desirable. This also casts doubt on any suggestion that the extension of civil partnership could be neutral toward marriage, rather than necessarily risk undermining it.

\section{Looking Ahead to the Court of Appeal's Decision}

The Steinfeld couple's appeal to the Court of Appeal is scheduled to be heard in November 2016. Understood in equality-based terms, their discrimination claim should be allowed on appeal and Andrews $\mathrm{J}$ was mistaken in her conclusion that the extension of civil partnership to opposite-sex couples was a matter of social policy for a democratically-elected government to address and not within the ambit of the Court's supervisory powers (para. 22). Yet, the impact on the broader public interest in marriage of allowing such a claim is critically complex, disputed, and uncertain. Whilst the equality-based nature of the claim avoids the need for the exercise of moral judgment about civil partnership, the ramifications for the institution of marriage and the regulation of cohabitees requires future consideration. This in part explains why it has always been Parliament that has reformed the law in this context. The other aspect of the explanation is that earlier reforms, such as the extension of marriage to same-sex couples were liberty-based, and not readily amenable to judicial determination.

But the foregoing discussion of assumptions made about the immutability and flexibility of the legal institutions that regulate adults' intimate relationships and the neglected public interest highlight one possible basis for rejecting the Steinfeld couple's appeal. During the debates over the Civil Partnership Bill that became the 2004 Act, Lord Lester suggested that civil marriage provided opposite-sex couples with the 'legal equivalent' of civil partnership (HL Deb 24 June 2004: Vol. 662 Col. 1407). It is notable that, in so suggesting, Lord Lester reversed his earlier position that opposite-sex couples should have access to civil partnership. The Court of Appeal might similarly seek to undercut the equality-based claim. Rather than being seen as necessitating access to civil partnership, the Steinfeld couple's argument for access to a modern equivalent to traditional marriage could be seen as just a demand for access to the more modern institution of marriage that eschews the anachronistic and 
patriarchal aspects to which they object. It is an open question whether marriage as an institution is yet sufficiently modernised to ground such a response, though the trend towards civil marriage, which, at 70 percent of all marriages, was a 'record proportion' in 2012 (Haskey, 2016, p. 57) certainly suggests it is at least on track.

\section{Bibliography}

Arden, Rt Hon. (2010). 'Peaceful of Problematic? The Relationship between National Supreme Courts and Supranational Courts in Europe', Yearbook of European Law, 3-20. Department for Culture, Media, and Sport. (2014). Civil Partnership Review (England and Wales) - A Consultation (London, HMSO).

Fenwick, H. (2012). 'What's Wrong With S.2 of the Human Rights Act?', UK Const. L. Blog (9 Oct 2012), available online: <http://ukconstitutionallaw.org>.

Haskey, J. (2016). 'Civil partnerships and same-sex marriages in England and Wales: a social and demographic perspective’, Family Law 46, 44-59.

Hellman, D. (2013). ‘Equality and Unconstitutional Discrimination’ in D. Hellman and S. Moreau (eds) Philosophical Foundations of Discrimination Law (Oxford: Oxford University Press) 51-70.

Joint Committee on Human Rights. (2011). HC 873-ii: Human Rights Judgments, uncorrected transcript of oral evidence (15 November 2011).

Lewis, J. (2007) 'The European ceiling on human rights', Public Law, 720-747.

Moreau, S. (2013). 'In Defense of a Liberty-based Account of Discrimination' in D. Hellman and S. Moreau (eds) Philosophical Foundations of Discrimination Law (Oxford: Oxford University Press) 71-86. 